Paidéia, 2001, 11(20), 85-98

\title{
A REPRESENTAÇÃo SOCIAL DO PSICÓLOGO E DE SUA PRÁTICA NO ESPAÇO PÚBLICO-COMUNITÁRIO' ${ }^{1}$
}

\author{
Carmen Ojeda Ocampo More ${ }^{2}$ \\ Aida C. Leiva \\ Luciana Vilela Tagliari \\ CFCH-Universidade Federal de Santa Catarina
}

\begin{abstract}
RESUMO: O objetivo deste artigo é apresentar dados de pesquisa sobre a Representação Social do Psicólogo e de sua prática. A amostra foi composta por funcionários, técnicos e pacientes que pela primeira vez procuravam o atendimento psicológico, em um posto de saúde da Prefeitura e Florianópolis, num total de 38 entrevistados. Utilizou-se um questionário de sentenças estruturadas. A sistematização dos dados obedeceu passos da análise compreensiva de base fenomenológica. Constatou-se que a Representação Social do Psicólogo é a de um profissional "que lida com problemas emocionais, que ajuda, orienta e conversa", estando sua prática associada a uma variedade de dificuldades, desconhecendo-se propostas de tratamento psicológico. Concluiu-se pela importância do reconhecimento da especificidade do trabalho do psicólogo na equipe de saúde, tanto pelas pessoas que procuram seus serviços, como pelo profissional que ali trabalha.
\end{abstract}

Palavras Chaves: Psicólogo, Representação social, Comunidade, Intervenção psicológica

\section{THE PSYCHOLOGIST SOCIAL REPRESENTATION AND HIS ACTIVITIES IN THE COMUNITARY CONTEXT}

\begin{abstract}
The objective of this paper is to present research data about Psychologist Social Representation and his activity. The sample was composed by professionals, health station employees and by people that for the first time searched for psychological assistance in a health center of Florianópolis, in a total of 38 interviewed. It was used a structured sentence questionnaires. The data systematization obeyed comprehensive analysis in a phenomenological base. Data showed that the Psychological Social Representation is of a professional "that deals with emotional problems, helps, orients and talks", with a practice associated with different difficulties, being psychological treatment proposes unknown. It was concluded that it is important to recognize the specificity of psychologist work in health team, by clients and other professionals.
\end{abstract}

Keys Words: Psicologist - Social Representation - Comunnity - Psychological Intervention

Os dados apresentados neste artigo são produto de uma pesquisa realizada no contexto comunitário, campo de nossas ações de intervenção, constituindo-se na base para um projeto maior de atuação e também para a fundamentação de um modelo de sistematização de intervenção psicológica a partir de centros de saúde comunitários.

A importância da mesma reside na possibili-

\footnotetext{
'Artigo recebido para publicação em outubro de 2001; aceito em fevereiro de 2002.

?Endereço para correspondência: Carmen L. Ojeda Ocampo More, Depto de Psicologia, Centro de Filosofia e Ciências Humanas, Universidade Federal de Santa Catarina, Campus Universitário, s/ $\mathrm{n}^{0}$, Trindade, Florianópolis, SC, Cep 88900-000, e-mail: cmore@ mboxl.ufsc.br
}

dade de estar oferecendo dados objetivos para reflexão e fundamentação da prática do psicólogo que atua no espaço público-comunitário e, também, na possibilidade de estar orientando atividades do profissional da Psicologia tanto em nível acadêmico quanto profissional, no sentido de estarmos atentos às peculiaridades das demandas no contexto comunitário.

O objetivo principal foi o de "detectar os níveis de saber que as camadas populares e a equipe de saúde possuem em torno do psicológico, do psicólogo e sua prática, para assim, tentar fazer uma ponte com o saber acadêmico já instituído". 


\section{Camen Ojeda Ocampo More}

As bases para sua realização tiveram como referência dois movimentos concomitantes no campo da produção de conhecimento, um na área da Saúde Mental e outro no campo da Psicologia Clínica, os quais foram ao encontro de nossa meta de atuação, que era de levar a Psicologia à comunidade, onde a figura do psicólogo era praticamente desconhecida.

O movimento na área da Saúde Mental tem como expoente principal, no Brasil, a questão da Reforma Psiquiátrica. A mesma aponta para a desospitalização, questionando tanto as instituições psiquiátricas e o aparelho manicomial quanto os próprios paradigmas que sustentam estas práticas, e enfatiza a procura de novas alternativas no atendimento assistencial-ambulatorial. Este movimento concretizou-se num projeto de lei de autoria de Delgado (1991), atualmente na fase de aprovação final no Congresso Nacional, que dispõe

[...] sobre a extinção progressiva dos manicômios e sua substituição por outros "recursos assistenciais", regulamentando a internação psiquiátrica compulsória (p.6).

Atendendo a isto, na $1^{\text {a. }}$ Conferência Estadual de Saúde Mental, realizada em 1992 na cidade de Florianópolis (SC), os profissionais envolvidos resolveram criar comissões municipais e estaduais de Saúde Mental multiprofissionais para se dedicarem ao estudo de medidas que pudessem acelerar o processo proposto pela Reforma e ao mesmo tempo incentivar o

"[...] desenvolvimento de ações e serviços de atenção em Saúde Mental, buscando a valorização do indivíduo e o resgate de sua cidadania" (p.4).

Assim, quando solicitados para uma atuação nesta rede integrada de assistência ambulatorial ao nível municipal, muitos questionamentos surgiram, suscitando a nossa reflexão no que diz respeito à atuaçăo da Psicologia de um modo geral, no espaço público comunitário, atendendo à demanda específica que procura os centros de saúde. Na área da Psicologia constatava-se um movimento de questionamento e reflexão sobre os problemas de atuação, principalmente do Psicólogo Clínico, e as bases teórico-científicas que sustentavam a sua prática quando solicitado a atuar fora dos espaços históricos e tradicionalmente constituídos para sua atuação.

Este movimento evidencia-se pelo aumento significativo de pesquisas, publicações e comunicações científicas na área de trabalho da Psicologia em Instituições Públicas. O conhecimento que sustenta a psicologia, de um modo geral, está sendo revisto à luz das novas dinâmicas sócio-culturais e econômicas, que se desenham e se impõem como realidades atuais. Constata-se que a eficiência do conhecimento psicológico, em termos de intervenção, parece perder-se na passagem do privado para o público.

A questão dos contrastes sociais influencia diretamente na demanda psicológica e é neste contexto que se impõe como necessidade a revisão dos parâmetros de sustentação teórico-metodológicos. Isto nos remete a pensar no desenvolvimento da Psicologia aqui no Brasil, e, principalmente no modelo acadêmico predominante, ou seja, a Psicologia Clínica. Segundo pesquisas, esta foi a área de estágio que teve e tem maior demanda nas universidades, sendo sustentada tanto pelo corpo docente, como pela escolha dos alunos (Carvalho, 1983; Mello, 1975).

A clínica tornou-se, assim, um modelo de atuação hegemônico do profissional recém-formado, levando a disseminação e ao fortalecimento de trabalhos em nível privado que, "de um certo modo, outorgavam identidade e segurança profissional" (Macedo, 1984, p7). No entanto, esse modelo de atuação clínica não tem apresentado a mesma eficácia, no sentido de uma prática que gere condições de uma escuta contextualizada, quando transposto para instituições que atendem populações desfavorecidas.

Acreditamos que isto é consequiência da própria história na qual a Psicologia Clínica arquiteta seu arcabouço teórico-metodológico, atendendo à demanda de classes privilegiadas em termos econômico-culturais, onde o problema básico a ser atendido é da ordem da inadequação individual às circunstâncias da vida. Assim, segmentos da população nos quais o problema principal é o da sobrevivência produto de um sistema sócio-político-cultural que não supre necessidades básicas do indivíduo, tais como 
moradia, higiene sanitária básica, emprego, etc. foram paulatinamente relegados nas formulações teórico-metodológicas de tratamento. Isto deixou em evidência uma práxis vinculada a determinadas camadas da população. A este respeito Macedo (1984) afirma que:

"[...] surgiram subculturas para as quais, a ajuda psicológica tem ficado a cargo de psiquiatras, clínicos gerais e tratamentos medicamentosos oferecidos pela Previdência Social, ... esse modelo tradicional tem relevado a uma relação patronal Psicólogo-cliente que foge à essência da atitude clínica." (p.13).

Soma-se a isto um aspecto característico da população que procura atendimento psicológico em espaços gratuitos. Segundo Larrabure (1982) a maioria desta população vem encaminhada por outras instituições, caracterizando-se por

\section{"[...] não estar realmente motivados para o atendimento, visto não compreender sua ne- cessidade e desconhecer o que é um serviço psicológico, uma vez que este tipo de traba- lho não tem repercussão no seu universo edu- cacional e cultural'.(p.63).}

Outro aspecto marcante desta população, seguindo a linha de pensamento da autora acima mencionada, é que a angústia psicológica é vivenciada ou sentida como conseqüência das difíceis condições impostas a ela e não como inadequações pessoais; assim, seus problemas não residem no seu interior, mas surgem de fora. Constata-se também

"[...] que as pessoas que procuram os serviços de saúde de um modo geral, estão mais orientadas para ação e esperam ver as coisas serem feitas, entregando ou delegando sua capacidade de compreensão e entendimento para o sistema". (p.64)

Percebemos assim, por um lado, as deficiências teórico-metodológicas na Psicologia Clínica em termos de uma atuação mais eficiente, no sentido de uma escuta mais contextualizada nas instituições públicas e à população que procura serviços especializados. Por outro lado, temos as próprias características da clientela que estão presentes no tipo do "pedido de ajuda" solicitado.

Em função desta realidade surge a necessidade de adequar ou flexibilizar os modelos teóricometodológicos. Ancona Lopez (1983), sugere que

"[...] os modelos a serem utilizados em Instituições de atendimento Psicológico gratuito, serão mais efetivos quando mais contextualizados, isto é, definidos a partir das características especificas de cada instituição e da população que procura os seus serviços". (p.41).

Cabe destacar que dados de pesquisa de Ancona Lopez (1983) mostram que modificações técnicas e metodológicas para adaptação à clientela numa clínica escola, tiveram repercussão direta no índice de desistências, as quais tornaram-se raras ou poucas. A hipótese que a pesquisadora levanta é que

“[...] as técnicas utilizadas se mostravam efetivas, no sentido de facilitar ao cliente a compreensão do atendimento que lhe seria oferecido, facilitando ao mesmo, condições para que optasse ou não por realizá-lo." (p.35).

Defrontamo-nos também com a necessidade de redimensionar o sentido do que é a Psicologia Clínica e como ela pode ser compreendida no contexto público-comunitário. Segundo Macedo (1984):

“[...] a clínica se distingue das demais áreas psicológicas, muito mais por uma maneira de pensar e atuar, do que pelos problemas que trata. O comportamento, a personalidade, as normas de ação e seus desvios, as relações interpessoais, os processos grupais evolutivos e de aprendizagem, são objeto de estudo, não só de muitos campos da Psicologia como também das ciências humanas èm geral". (p.9).

A compreensão e intervenção nos problemas que atingem o ser humano, visando o bem estar indi- 


\section{Carmen Ojeda Ocampo More}

vidual e social, é o que diz respeito à natureza da Psicologia e, por conseqüência, a sua prática. Complementando, encontramos no campo teórico o pensamento de Bohoslavky (1968), que vai ao encontro da necessidade de uma nova significação da Psicologia Clínica, no sentido de deixar de ser uma área específica de atuação e que lhe dá identidade, afirmando:

\section{"[...] a Psicologia Clínica se caracteriza por ser uma estratégia de abordagem do objeto de estudo, que é a conduta dos seres huma- nos, [...] falar de estratégia implica sublinhar um tipo de "mirada de" e de "operação" so- bre as condutas humanas (p.4).}

Concomitantemente a isto, e guiados pelo nosso objetivo de pesquisa, temos a teoria das Representações Sociais que se evidencia pela produção de um conhecimento, nas mais diversas áreas das Ciências Humanas, onde as representações são objeto central de estudos ou são utilizadas como instrumento necessário para acessar o objeto em questão. Estudos neste campo, como os de Moscovici et alii (1984), têm se destacado pela riqueza de produção empírica na procura de uma reflexão teóricometodológica mais contextualizada às realidades de atuação.

Jodelet (1984), continuadora das idéias de Moscovici, numa proposta de sistematização do campo das Representações Sociais afirma que:

"O conceito de Representação Social designa uma forma especifica de conhecimento, o saber do senso comum, cujos conteúdos manifestam a operação de processos generativos e funcionais socialmente marcados; mais amplamente, designa uma forma de pensamento social" (p.361,2).

Este conceito contempla as modalidades de pensamentos práticos orientados para a comunicação, a compreensão e o domínio do ambiente social, material e ideal.

Representação Social alude, então, a "l...] uma forma de conhecimento socialmente elaborada e compartilhada, que concorre para a construção de uma realidade comum a um conjunto social" (Jodelet, 1989. p.36).

Dentro do processo formador das Representações Sociais, cabe destacar a "ancoragem" e a "objetivação", como aspectos constitutivos de um movimento único e dinâmico que contextualiza essa forma específica de conhecimento.

A ancoragem consiste na integração cognitiva do objeto representado, sejam idéias, acontecimentos, pessoas, relações, etc, a um sistema de pensamento social pré-existente e nas transformações implicadas neste processo (Jodelet, 1984). Isto implica dizer que as representações já estruturadas podem funcionar também como sistema de referência para novas representações.

A este respeito Moscovici (1984) afirma " [...] que ancorar é classificar e denominar". (p.36), pois aquilo que não é classificado nem denominado não existe, sendo ao mesmo tempo ameaçador. Assim, a "classificação" é entendida como aquela que se dá mediante a escolha de um paradigma ou decisão se o objeto focado pode ou não ser incluído na classe em questão.

"Nesta operação de classificação, se faz uma comparação generalizadora ou particularizadora, através da qual se estipula ou determina se o objeto é incluido ou afastado da categoria de referência, com base na divergência ou concordância com o objeto em estudo". (p.37)

Outra operação presente na ancoragem é a "denominação" que, de acordo com Moscovici (1984),

"ao denominar alguma coisa, nós a tornamos de um denominador perturbador para dotála de uma genealogia e incluí-a num complexo de palavras específicas, para localizá-la, de fato, na matriz de identidade de nossa cultura".(p.38). 
Portanto, uma vez denominada uma pessoa, ou coisa, esta adquire certas características, tendências etc., tornando-a distinta das outras pessoas ou coisas, transformando-se em objeto de uma convenção entre aqueles que a adotam e a partilham.

A objetivação, por sua vez, consiste numa operação "imaginante e estruturante", pela qual se dá uma forma ou figura específica ao conhecimento acerca do objeto, tornando concreto o conceito abstrato e assim, materializando a palavra. (Jodelet, 1984). Segundo Moscovici (1984), objetivar e reproduzir um conceito em uma imagem seria também "reabsorver um excesso de significado". $O$ autor afirma:

"Aquelas (palavras) que, devido a sua capacidade para serem representadas, tiverem sido selecionadas.. .[...] são integradas ao que chamei de um padrão de núcleo figurativo, um complexo de imagens que reproduz. visivelmente um complexo de idéias... [...] Uma vez que a sociedade tenha adotado tal paradigma ou núcleo figurativo, fica mais fácil falar sobre qualquer coisa que possa ser associada ao paradigma e, por causa desta facilidade, as palavras referentes a ele são usadas mais freqüentemente" (p.41).

Dissertamos até agora, dentro do conceito das representações sociais, certos aspectos constitutivos do mesmo que vão ao encontro tanto de nosso objetivo de pesquisa quanto ao fenômeno a ser pesquisado. A importância deste estudo reside na possibilidade de realizar, de modo contextualizado, uma série de reflexões teórico-práticas que possam se traduzir numa produção de conhecimento coerente com a realidade de atuação.

Assim, acreditamos que para rever nossos referenciais da atuação clínica, e para melhor adaptálos a esta nova realidade, se faz necessário pesquisar e conhecer qual "o saber" sobre o psicológico, o psicólogo e qual o significado da ajuda psicológica das camadas populares e da equipe de saúde. Isto é com $o$ intuito de termos elementos concretos que auxiliem no redimensionamento do atuar clínico, a partir do contexto de atuação e para que possamos estabelecer pontes científicas com o conhecimento psicológico já instituido cientificamente.

\section{Metodologia}

A pesquisa desenvolveu-se no Posto de Saúde do bairro Saco dos Limões, pertencente ao município de Florianópolis. Dentro dos serviços prestados pelo mesmo temos vacinação, coleta de exames (sangue, urina e fezes) e atendimento ambulatorial nas especialidades de clínica geral, ginecologia e pediatria. A comunidade atendida pelo posto caracteriza-se, basicamente, por dois extremos: classe média e bolsões de grande carência. A população que procura o serviço do mesmo, na sua maioria, tem nível de instrução primária ou é semi-analfabeta e pertence a uma classe de baixa renda.

A amostra pesquisada obedeceu a parâmetros previamente estabelecidos, sendo entrevistados um total de 38 sujeitos, ficando assim configurada: 13 técnicos (escriturárias, técnicas de enfermagem, correspondendo a $92 \%$ dos funcionários do posto); 5 profissionais de nível universitário (médicos, enfermeiros e bioquímicos, perfazendo $55 \%$ dos profissionais que atuavam no posto); e 20 pessoas da comunidade (que procuravam pela primeira vez o serviço de Psicologia, representando $100 \%$ da população, a partir da média de três meses de atendimento de pacientes novos). No caso de adolescentes e crianças, eram entrevistados os familiares ou responsáveis que os acompanhavam.

Foi utilizado um questionário de sentenças estruturadas (anexo 1), sendo que o mesmo teve uma variação de acordo com o grupo de entrevistados, após estudo piloto, no sentido de uma melhor adaptação das sentenças aos níveis de escolaridade dos grupos. Todas as entrevistas foram gravadas e transcritas na íntegra.

Para a sistematização dos dados utilizamos procedimentos de pesquisa na linha das Representações Sociais. Basicamente, o tratamento dos dados teve como referência as etapas propostas por Bernardes (1991) para análise compreensiva de base fenomenológica.

\section{Análise e Discussão dos Dados}

Para facilitar a compreensão dos dados obtidos seguimos a ordem das perguntas realizadas e suas categorias, destacando-se as principais tabelas de 
resultados. Concomitantemente, foram sendo apontados também aspectos relevantes observados na nossa prática junto ao posto que complementam a análise e discussão deste trabalho.

\section{O encaminhamento para atendimento psicológico}

Questão $\mathrm{n}^{\mathrm{Q}} 1$, respondida pelas pessoas que procuravam o atendimento psicológico pela primeira vez: "Por quem você foi encaminhado ao serviço de Psicologia"?

\begin{tabular}{l|c|c}
\hline \multicolumn{3}{c}{ Quem encaminha } \\
\hline Categoria & $\begin{array}{c}\text { Freq. de } \\
\text { resposta }\end{array}$ & $\mathbf{( \% )}$ \\
\hline Médicos & 8 & 40 \\
Iniciativa própria & 4 & 20 \\
Familiares & 4 & 20 \\
Técnicos do posto & 3 & 15 \\
Escola & 1 & 5 \\
Total & 20 & 100 \\
\hline
\end{tabular}

Os encaminhamentos tiveram uma relação direta com o pedido de ajuda que a população procurava na Psicologia. A maioria das pessoas (80\% da amostra) que solicitaram o serviço, não o fez por iniciativa própria, vieram a pedido "de outros". Evidenciamos que as pessoas não compreendiam e/ou desconheciam o que fazia o profissional da psicologia numa equipe de saúde, tendo isto um impacto tanto na compreensão do trabalho proposto quanto na motivação para o tratamento, já que muitos iam ao atendimento porque outro profissional havia indicado e não por iniciativa própria. Pesquisas como a de Larraburre (1982), apontam também para este dado do encaminhamento como uma realidade das instituições de atendimento gratuito.

Este aspecto teve uma repercussão no nosso atendimento na medida em que as pessoas traziam um modelo de relação profissional já internalizado, propondo ou procurando no mesmo "respostas prontas" e "rapidez no tratamento". Associado a isto, tínhamos as características próprias desta população com relação ao modo de vivenciar o conflito psicológico e a resolução do mesmo, estando orientada mais para a ação, esperando ver as coisas serem feitas para si. (Larrabure, 1984).

Isto evidencia a realidade de um sistema so- cial e político de saúde ao qual as pessoas se submetem, no sentido de que "a instituição tem que fazer por eles", por não terem outras possibilidades de atendimento mais condizentes com a realidade em que elas se inserem.

No item "familiares" da questão acima, a mãe foi a principal encaminhadora. É importante aqui assocịar à instituição Escola a figura materna, que se alia à mesma no "pedido de ajuda para resolver o problema do filho". Neste tipo de encaminhamento havia implícito um pedido de solução para o problema. No entanto, os pais traziam os filhos para o atendimento psicológico sem um conhecimento das suas dificuldades ou dos problemas apontados pela esco1a. Da mesma forma, os professores que encaminhavam seus alunos delegavam também, ao Psicólogo, a responsabilidade de uma solução.

A categoria encaminhamento nos defrontou com o "desconhecimento" do psicólogo como profissional da saúde, o que nos incitou a reflexão sobre a construção da Representação Social do Psicólogo, em termos de estar detectando quais os aspectos utilizados como referência para a ancoragem e a objetivação para as respostas de nosso instrumento de pesquisa. Cabe aqui destacar o que Jodelet (1984) aponta como sistema de referência para novas representações, o qual se daria pelo conhecimento social pré-existente, seja de acontecimentos, pessoas, relações, etc. Assim, percebemos que aspectos como desconhecimento do psicólogo, respostas prontas, rapidez no tratamento, estavam presentes quando da solicitação pelos nossos serviços, constituindo-se em elementos valiosos de análise para perceber as referências que poderiam estar presentes na construção da Representação Social do Psicólogo.

Questão $\mathrm{n}^{2} 2$, respondida pelos profissionais: "O que você sabe ou pensa da Psicologia como ciência?", e pelos técnicos: "O que você sabe ou pensa que é a Psicologia?" 


\begin{tabular}{l|c|c|c|c}
\hline \multicolumn{1}{c|}{ Categorias } & \multicolumn{2}{c|}{ Técnicos } & \multicolumn{2}{c}{ Profissionais } \\
\cline { 2 - 5 } & $\begin{array}{l}\text { Freq. de } \\
\text { resposta }\end{array}$ & $(\%)$ & $\begin{array}{c}\text { Freq. de } \\
\text { resposta }\end{array}$ & $(\%)$ \\
\hline Estuda as pessoas & 07 & $54 \%$ & 03 & $60 \%$ \\
Lida com problemas emocionais & 10 & $77 \%$ & 02 & $40 \%$ \\
Ajuda/orienta & 06 & $46 \%$ & - & - \\
Companheirismo & 03 & $23 \%$ & - & - \\
Não sei & 02 & $15 \%$ & - & - \\
Trata de pessoas agressivas & 01 & $08 \%$ & - & - \\
Área da Medicina & 01 & $08 \%$ & - & - \\
Estuda a relação das pessoas & - & - & 01 & $20 \%$ \\
\hline
\end{tabular}

Observamos que no grupo dos profissionais, a noção de Psicologia caracterizou-se, por um lado, como uma ciência de caráter abrangente que "estuda as pessoas" e, por outro, contextualizada por "lidar com problemas emocionais". Esta concepção de Psicologia, presente no discurso dos profissionais, se constituiu num elemento importante em termos de referência para a objetivação da Representação Social do Psicólogo, tanto para os técnicos do posto como para os pacientes. De certo modo, o discurso do profissional fornecia as bases para uma forma ou figura específica acerca do psicólogo, tornando concreto um elemento pouco conhecido no universo conceitual das pessoas.

Nos funcionários de nível técnico aparece um número maior de categorias para conceitualizar a Psicologia. No entanto, para a maioria deste grupo a mesma foi considerada uma área profissional que lida eminentemente com problemas emocionais ( $77 \%$ da amostra), sendo que as demais categorias agruparam-se em torno de "estuda a pessoa", "ajuda e orienta" e "companheirismo". A este respeito, o depoimento de uma técnica do posto sintetiza muito bem o saber do grupo como um todo, com relação à Psicologia:

"Para mim Psicologia é quando a pessoa está se sentindo sozinha, precisando até mesmo de companhia... de alguém para conversar. Porque muitas vezes as pessoas aparecem aqui no posto, às vezes não tem doença. Vem aqui, choram, tem um monte de problemas e contam monte de coisas. A gente só conversa e pronto! Eles ficam numa boa! Eu acho que a Psicologia para mim é mais companheirismo, é mais ajudar a pessoa, no íntimo dela, ajudar a pessoa não corporalmente,... pela mente da pessoa, estudar o que as pessoas pensam, como elas vivem, o que elas sentem, o que elas precisam no seu intimo".

Percebemos nos técnicos uma conceituação da Psicologia a partir da vivência prática, destacando no depoimento acima o aspecto que "após conversar as pessoas ficam numa boa", aludindo assim a uma resolução rápida ou momentânea. Esta visão, presente na maioria dos pacientes, dificultou em certa medida a compreensão de nossa proposta de trabalho, que caminhava numa linha diferente da dos profissionais do posto.

Outro aspecto que aparece delineado nesse depoimento, e que é compartilhado pela maioria dos profissionais, é a separação entre corpo e mente. $\mathrm{Ou}$ seja, a intervenção psicológica restrita à mente. Isto fica evidente no depoimento de um profissional quando diz:

"A Psicologia como ciência ... primeiro que é uma coisa que pode ser importante. E eu acho que ela abrange mais o comportamento das pessoas, que é aí que ela entra.. não onde já tem doenças, não no nível de doença mental de origem orgânica..."

Somente dois profissionais da amostra levantaram a questão da Psicologia como ciência que lida com a parte emocional associada ao lado somático. Um deles afirma: 
"Psicologia é uma ciência que se preocupa ou tenta entender e ajudar o ser humano com relação aos aspectos psicológicos dele, aspectos esses que seguramente vão interferir no lado somático, exemplo a hipertensão, diabetes, etc...".

\section{A Representação Social da Prática do Psicólogo}

Com o intuito de preservar a fidelidade dos depoimentos, foram estabelecidas 14 categorias. Questão $\mathrm{n}^{\mathrm{g}} 2$, respondida pelos três grupos que conformam a amostra: "Você sabe o que faz um psicólogo?"

\begin{tabular}{l|c|c|c|c|c|c}
\hline \multicolumn{1}{|c|}{ Categorias } & \multicolumn{2}{c|}{ Pacientes } & \multicolumn{2}{c|}{ Técnicos } & \multicolumn{2}{c}{ Profissionais } \\
\hline & $\begin{array}{c}\text { Freq de } \\
\text { resposta }\end{array}$ & $(\%)$ & $\begin{array}{c}\text { Freq. de } \\
\text { resposta }\end{array}$ & $(\%)$ & $\begin{array}{c}\text { Freq. de } \\
\text { resposta }\end{array}$ & $(\%)$ \\
\hline Ajuda/orienta & 16 & 80 & 09 & 69 & 04 & 80 \\
Ensina & - & - & - & - & 02 & 40 \\
Estuda as pessoas & 05 & 25 & - & - & - & - \\
Conversa & 04 & 20 & 08 & 61 & - & - \\
Faz tratamento & 01 & 5 & - & - & - & - \\
Terapia & - & - & 05 & 38 & - & - \\
Trata de pessoas com problemas & - & - & 03 & 23 & - & - \\
Lida com o emocional & - & - & - & - & 02 & 40 \\
Alteração do comportamento & - & - & - & - & 01 & 20 \\
Não interfere a nível mental & - & - & - & - & 01 & 20 \\
Lida com os nervos & - & - & 02 & 15 & - & - \\
Não sei & - & - & 02 & 15 & - & - \\
Tira traumas & 02 & 10 & - & - & - & - \\
Coloca a pessoa em ordem & 01 & 5 & - & - & - & - \\
\hline
\end{tabular}

Percebemos uma maior semelhança entre os técnicos e pacientes e somente uma categoria em comum com os profissionais. A categoria 1 desta questão (ajuda/orienta), foi a que contextualizou a prática do psicólogo, recebendo maior porcentagem de respostas nos três grupos $(80 \%, 69 \%$ e $80 \%$ respectivamente). Observamos percentuais iguais no grupo dos pacientes e profissionais, o que nos remete às reflexões anteriormente levantadas com relação à influência do discurso do profissional que encaminha, em termos da configuração da Representação Social do Psicólogo.

Entendemos que, fazendo parte deste processo, ancorado e objetivado na categoria 1 desta questão ("ajuda/orienta"), estava a necessidade de um pedido de ajuda expresso pela maioria das pessoas que compuseram a amostra, destacando que de um total de 38 sujeitos da mesma, 34 pertenciam ao sexo feminino.

No grupo dos pacientes, todas as mulheres entrevistadas eram do lar, faxineiras ou lavadeiras, sendo que as atividades externas ao lar se constituíam numa extensão do papel domiciliar e num com- plemento econômico do mesmo.

Pesquisa de Larrabure (1982) evidencia que as mulheres nas camadas populares estão acostumadas a depender dos outros e a sobreviver em condições difíceis e até adversas, tanto em termos familiares (agressão, alcoolismo do marido), como sociais (falta de condições de higiene básica, moradia, alimentação, etc.). Assim, suas inquietações pessoais não encontram canais de derivação e sua insatisfação do cotidiano é pouco compreendida.

Em certa medida, para as mulheres de nossa amostra, solicitar ajuda e orientação podia ser entendido como um comportamento de dependência, já que procurar ou obter informação era vivenciado como uma forma de desenvolver seu papel materno, para melhorar a situação familiar da qual elas se sentiam diretamente responsáveis.

Percebíamos também que no pedido de ajuda e orientação destas mulheres estava presente uma atitude passiva de receber informações, até sem muitos questionamentos pessoais e, quando não recebiam as mesmas no contexto de suas experiências, fi- 
cava difícil entender nossa proposta de trabalho, onde eram convidadas a serem participantes ativas. Defrontamo-nos com a necessidade de explicitar as funções do psicólogo e sua prática com uma linguagem que se apoiasse nas experiências de vida dos sujeitos, resgatando a idéia de participação no processo de ajuda e orientação, dando as bases para a possibilidade de transformação tanto em nível individual como familiar.

Observamos que a Representação Social sobre a prática do Psicólogo, seja dos profissionais ou dos técnicos, neste caso, não era por si só um ele- mento definidor da mesma. Era sim, uma referência em torno da qual se aglutinaram outras experiências de vida que, no final das contas, eram constitutivas da subjetividade individual como um todo.

\section{Representação social da necessidade do atendimen- to psicológico}

As reflexões do item anterior nos remetem à questão 3: "No seu entender que pessoas precisariam de psicólogo?" (tabela abaixo) que obteve a maior quantidade de categorias. As mesmas surgiram da dificuldade de agrupar núcleos de significação pela freqüência de respostas.

\begin{tabular}{l|c|c|c|c|c|c}
\hline \multicolumn{1}{c|}{ Categorias } & \multicolumn{2}{|c|}{ Pacientes } & \multicolumn{2}{c|}{ Técnicos } & \multicolumn{2}{c}{ Profissionais } \\
\cline { 2 - 7 } & $\begin{array}{l}\text { Freq de } \\
\text { resposta }\end{array}$ & $\begin{array}{l}\text { Freq de } \\
\text { resposta }\end{array}$ & $\begin{array}{l}\text { Freq de } \\
\text { resposta }\end{array}$ & $(\%)$ \\
\hline Com problemas emocionais & 10 & $50 \%$ & 07 & $54 \%$ & 03 & $60 \%$ \\
Desorientadas e angustiadas & 07 & $35 \%$ & 02 & $15 \%$ & - & - \\
Nervosas & 04 & $20 \%$ & - & - & 01 & $20 \%$ \\
Que não gostam de si mesmas & 01 & $5 \%$ & 01 & $8 \%$ & - & - \\
Que não são capazes & 01 & $5 \%$ & - & - & - & - \\
Agitadas & 01 & $5 \%$ & - & - & - & - \\
Revoltadas & 01 & $5 \%$ & 02 & $15 \%$ & - & - \\
Que não medem conseqüências & 01 & $5 \%$ & - & - & - & - \\
Comportamento estranho & 01 & $5 \%$ & - & - & - & - \\
Maioria da população & 03 & $15 \%$ & 04 & $31 \%$ & 02 & $40 \%$ \\
Que precisam conversar & - & - & 05 & $36 \%$ & 01 & $20 \%$ \\
Que precisam orientação/ajuda & - & - & 04 & $31 \%$ & - & - \\
Que não aceitam as coisas & - & - & 01 & $8 \%$ & - & - \\
Que querem se autoconhecer & - & - & 01 & $8 \%$ & - & - \\
Pessoas normais & - & - & 01 & $8 \%$ & - & - \\
Carentes & - & - & 01 & $8 \%$ & - & - \\
Desajustadas & - & - & - & - & 01 & $20 \%$ \\
Queprocisamdeconhecimentos técnicos & - & - & - & - & 01 & $20 \%$ \\
Distúrbios de aprendizagem & - & - & - & - & 01 & $20 \%$ \\
Alterações de comportamento & - & - & - & - & 01 & $20 \%$ \\
\hline
\end{tabular}

Em termos percentuais "Pessoas com problemas emocionais" obteve maior concentração de respostas em cada grupo (pacientes 50\%, técnicos $54 \%$ e profissionais $60 \%$ ); o restante das categorias recebeu percentuais diferentes, dependendo do grupo.

Assim, nos dados dos pacientes encontramos que as categorias "Desorientadas e angustiadas" e "Nervosas" receberam uma percentagem significativa (35\% e $20 \%$ respectivamente). Já nos técnicos, temos as categorias "Que precisam conversar" e "Que precisam de orientação/ajuda") que não aparecem nc grupo dos pacientes. No grupo dos profissionais outras categorias foram observadas, tais comc "Desajustadas"; "Que precisam de conhecimentc técnico" e "Alterações do comportamento".

Exemplificando esta questão, temos o depoimento de um profissional que disse:

"justamente essas... crianças. Minha área $\epsilon$ mais infantil, crianças que apresentam dis. 
túrbios de aprendizado. O que eu encaminho: distúrbios de aprendizado, alterações do comportamento e distúrbios emocionais, gerados principalmente pela família ... É só nessa área que vejo a Psicologia, se existir outra coisa, até gostaria de saber... "

A análise desta questão nos remete à multiplicidade de situações no campo comportamental e emocional em que o psicólogo poderia estar presente, variando de um grupo para outro a significação, a importância e o conhecimento que possam vir a ter da Psicologia. Esta variedade de possibilidades de atuação do psicólogo tinha uma correlação tanto com as vivências individuais quanto com as experiências do grupo social ou rede sociométrica ao qual pertenciam. Isto também foi confirmado pela nossa atuação através da diversidade de queixas, encaminhamentos ou motivos para a consulta.

Configurava-se assim uma visão do papel do psicólogo, de certo modo fragmentado nas suas atribuições de acordo com a significação dos grupos. Aparecia uma valorização de situações de acordo com o interesse, individual ou social, desconhecendo-se, de certo modo, a especificidade do psicólogo.

Se por um lado percebíamos essa fragmentação, por outro, evidenciávamos um dado muito importante em termos de caracterização da demanda com relação à Psicologia. Delineava-se assim o perfil do psicólogo necessário neste contexto: a figura de um "Psicólogo Clínico Geral". Sabíamos que não existia esta denominação em termos oficiais ou no cotidiano da cultura psicológica. No entanto, acreditamos que era o que melhor se adaptava a essa realidade, no sentido de não fragmentar a escuta da comunidade, pelas formações do profissional da psicologia (infantil, adolescente, adulto).

Isto nos levou necessariamente a repensar o que é "Psicologia Clínica", sendo que a visão proposta por Bohoslavky (1968) e Macedo (1984) auxiliounos a resignificá-la, no sentido de que a clínica se distingue das demais áreas psicológicas ou humanas, de um modo geral, muito mais por uma maneira de pensar e atuar do que pelos problemas que trata. Assim, a clínica caracterizaria-se por uma estratégia de estar pensando e atuando sobre os problemas nas mais variadas situações e nos mais variados contextos.

\section{Representação Social sobre as diferenças entre Psicólogo, Psiquiatra e Médico}

No que diz respeito ao conhecimento sobre as diferenças entre psicólogo, psiquiatra e médico clínico, tanto na equipe de saúde do posto, como nos pacientes, evidenciou-se uma certa confusão em termos de especificidade ou área profissional. O Psicólogo era confundido como sendo "um médico diferente", sendo isto agrupado na "categoria que não precreve medicação" e que não tínha relação nenhuma com o trabalho do psiquiatra e o médico, ou diretamente não sabiam o que ele fazia. Destacamos em continuação a tabela da questão respondida pelos pacientes que procuravam o atendimento psicológico pela primeira vez: "No seu entender, qual a diferença entre psicólogo, psiquiatra e médico de um modo geral"?

\begin{tabular}{l|c|c|c|c|c|c}
\hline \multirow{2}{*}{ Categorias } & \multicolumn{2}{|c|}{ Psicólogo } & \multicolumn{2}{c|}{ Psiquiatra } & \multicolumn{2}{c}{ Médico } \\
\cline { 2 - 7 } & $\begin{array}{l}\text { Freq de } \\
\text { resposta }\end{array}$ & $(\%)$ & $\begin{array}{c}\text { Freqde } \\
\text { respasta }\end{array}$ & $\begin{array}{c}\text { Freq de } \\
\text { resposta }\end{array}$ & $(\%)$ \\
\hline Receita medicação & - & - & 03 & $15 \%$ & 03 & $15 \%$ \\
Não prescreve medicação & 04 & $20 \%$ & - & - & - & - \\
Problemas mentais & 02 & $10 \%$ & 12 & $60 \%$ & - & - \\
Problemas emocionais & 03 & $15 \%$ & - & - & - & - \\
Aconselha / ajuda / ensina & 08 & $40 \%$ & - & - & - & - \\
Estuda as pessoas/conversa & 06 & $20 \%$ & - & - & - & - \\
Problemas mentais graves & - & - & 01 & $5 \%$ & - & - \\
Problemas mentais leves & 01 & $5 \%$ & - & - & - & - \\
Doença física & - & - & - & - & 12 & $60 \%$ \\
Examina / encaminha & - & - & - & - & 05 & $38 \%$ \\
\hline
\end{tabular}


Observamos que as categorias "orientalajuda/ensina"; "Estuda as pessoas/conversa", e "não receita medicação" ( $80 \%)$, concentram a maior porcentagem de respostas, em termos de especificidade. Já para o Psiquiatra e o Médico foram utilizadas, ao todo, três categorias, sendo que o primeiro é identificado por $60 \%$ do grupo como um profissional que lida com doença mental, e o segundo que trata de doença física $(60 \%)$, que examina e encaminha.

No grupo dos técnicos, aconteceu algo similar ao anterior em relação à quantidade de categorias, sendo o psicólogo e psiquiatra os que concentram o maior número. O Psicólogo foi identificado por: "lidar com problemas emocionais, ajudar, orientar e conversar". Já o Psiquiatra, por tratar de problemas mentais e medicar. O Médico foi relacionado à doença física e ao encaminhamento para exames.

Cabe chamar a atenção para a similaridade de categorias em comum entre os técnicos do posto e os pacientes, tais como "ajuda orienta e conversa",

Para os profissionais, o Psicólogo foi identificado na área da prevenção dos distúrbios, sejam eles emocionais ou comportamentais (60\% do grupo) e por lidar com casos mais leves, em termos de perturbação mental. Ao Psiquiatra foi atribuído a especificidade de dar medicação ( $100 \%$ do grupo) e atender casos mentais mais graves $(60 \%)$.

Os dados deste último grupo incitaram uma série de reflexões, no sentido de estar pensando junto com esses profissionais a idéia de prevenção presente nas ações dos mesmos, com o intuito de unificar esforços que convergissem nessa perspectiva na equipe do Posto. Assim, poderíamos estar dimensionando os serviços que o mesmo presta à população, no sentido de não ser um centro exclusivo para tratamento da doença e sim um centro para promover a saúde.

O conjunto dos dados relativos à diferenciação entre os três profissionais indagados foi o que nos permitiu ter acesso às outras rêpresentações, ainda que elementares, dos integrantes de uma equipe de saúde num posto, dando condições tanto para corroborar a Representação Social do Psicólogo, como para ter acesso ao conhecimento das especificidades de uma equipe multidisciplinar.

Este aspecto das especificidades de uma equi- pe e sua integração é um dos temas que tanto a Psicologia quanto outras áreas da Saúde têm-se debruçado, com o objetivo de viabilizar as equipes multidisciplinares para atingir o grande desafio que é a interdisciplinaridade de seus integrantes, dando bases para a construção de um contexto de diálogo e reflexão interdisciplinar.

Acreditamos ser o psicólogo um profissional do vínculo, e que seu trabalho e sua efetividade terão uma relação direta com a construção do mesmo, seja com os pacientes, grupos ou equipe de saúde. Cabe ao profissional da psicologia a possibilidade de ser um catalizador de recursos e habilidades das pessoas que procuram seus serviços e dos integrantes de uma equipe de saúde, para favorecer um melhor reconhecimento entre os mesmos e assim poder estabelecer objetivos em comum, condizentes com a realidade na qual estão inseridos.

"Mostrar-se para o outro", em termos de objetivos e especificidade de seu trabalho na equipe seria o passo inicial para a interdisciplinaridade, a qual não precisa ser necessariamente definida ou estabelecida a priori. Ela se constitui e se instrumentaliza na medida em que há um reconhecimento dos integrantes de uma equipe e se sustentará pela aceitação das diferenças e não por temor a elas. Acreditamos que se abrem caminhos de pesquisa no âmbito das Representações Sociais e especificamente do Psicólogo, nos mais diversos contextos em que ele venha a atuar, pois assim se terão elementos coerentes sobre os quais poderá propor seus objetivos e ações.

\section{Outras representações complementares ao tema}

A questão 6 sobre: "Qual dos seguintes problemas você tentaria resolver primeiro: 1) Doença Fisica; 2) Trabalho e moradia; 3) Conflitos pessoais e familiares e 4) Todos juntos?", respondida pelo grupo dos pacientes e técnicos, teve como objetivo detectar as prioridades da população em termos de resolução de problemas, visando contextualizar os dados das pesquisas de Macedo (1984); Ancona Lopez (1984), Larrabure (1982).

A inclusão dos técnicos nesta questão foi por serem eles a primeira referência no posto para a clientela que procura ajuda nos serviços que o mesmo 


\section{Carmen Ojeda Ocampo More}

presta, fornecendo assim dados comparativos como também influências deste grupo nas prioridades da população. Sabíamos também que esta questão em outro contexto ou tempo, no grupo dos pacientes, revelaria outras prioridades, e que os dados que emergiram evidenciaram necessidades atuais de vida.

Assim, no grupo dos pacientes, $40 \%$ alegou que tentaria resolver primeiro os "conflitos pessoais e familiares", deixando com o mesmo peso as categorias, "Doença física" e "Trabalho e moradia". Esta avaliação nos remete a pensar na característica da amostra com relação ao sexo e profissão, a qual estava composta por mulheres de baixa renda, mães e donas de casa, já mencionado anteriormente.

Familiarmente, o pai ou companheiro, assume o papel de provedor econômico principal, deixando à mulher os cuidados e responsabilidades referentes à criação e educação dos filhos, ainda que ela tenha um serviço extra-casa. Percebíamos que a questão do trabalho ou moradia, bem como a doença física, não tinham peso tão decisivo como os problemas familiares e individuais, os quais pertenciam na realidade ao universo de atuação da mulher. $O$ pedido de ajuda para resolver esses problemas se justifica pelos benefícios que poderiam trazer a ela e à vida familiar ou de certa forma reservar para si própria algum tempo de atenção.

Nos grupos dos técnicos do posto a prioridade foi dada aos problemas de ordem física ( $38 \%$ da amostra), sendo que a categoria "conflitos pessoais ou familiares" e "trabalho e moradia", receberam a mesma valoração em termos percentuais. Neste grupo, também eminentemente feminino, o campo de atuação em nível profissional estava determinando, em certo sentido, a prioridade de resolução de problemas.

O conjunto dos dados levaram-nos a refletir sobre o posto de saúde como um espaço onde o médico é a referência principal. Este profissional atende a um "pedido específico", existindo outras demandas implícitas a ele, tais como o "pedido de atenção psicológica", sendo que o mesmo não é contemplado por não fazer parte da realidade do posto, em termos profissionais de referência.

Acreditamos que muitos dos questionamentos aqui levantados poderiam gerar outras discussões ou outros enfoques. No entanto, pensamos que este pro- jeto foi um movimento inicial que serviu de base para um projeto maior: o de estar repensando a prática clínica, junto às camadas populares, em termos de uma melhor sistematização metodológica para intervenção psicológica propriamente dita.

Assim, o estudo da Representação Social do Psicólogo no Posto de Saúde tornou-se necessário para poder sustentar, de modo mais contextualizado, questionamentos que emergem da atuação junto a Postos de Saúde comunitários.

\section{Conclusões}

A análise dos dados desta pesquisa sobre Representação Social do Psicólogo permite evidenciar que nela convergem uma série de outras representações compartilhadas pelo grupo de entrevistados, que serviram de ancoragem e objetivação para a figura do Psicólogo.

Assim, a Representação Social que se configurou a partir dos depoimentos dos três grupos de entrevistados é a de um "profissional que lida com problemas emocionais e que ajuda/orienta e conversa". Destacam-se aqui, as influências do discurso dos profissionais, principais encaminhadores, em torno do qual foram se objetivando as respostas sobre o psicólogo, nos outros grupos que fizeram parte da amostra. No entanto, evidencia-se que, apesar desta objetivação, não se tem presente um conhecimento real do psicólogo. Acreditamos que isto é produto da falta deste profissional nas equipes profissionais dos postos de saúde da Prefeitura de Florianópolis, onde somente o médico é a referência principal, priorizando-se em certa medida os aspectos biológicos em detrimento dos aspectos emocionais ou psicológicos.

Com relação à prática do Psicólogo, constata-se uma multiplicidade de situações no campo comportamental e emocional em que o psicólogo poderia estar presente, variando de um grupo para outro em termos de valoração ou conhecimento. Esta multiplicidade de possibilidades de atuação do psicólogo está estreitamente relacionada às experiências individuais e às vivências decorrentes do grupo social no qual as pessoas estão inseridas. É a partir destas referências que se prioriza uma possibilidade de atuação do psicólogo, contextualizada na queixa 
ou motivo da consulta.

Constata-se assim, uma visão fragmentada do psicólogo na amostra, no que diz respeito a suas atribuições. O perfil do profissional necessário neste contexto seria a figura de um Psicólogo Clínico Geral, no sentido de uma melhor escuta da demanda e principalmente para não reproduzir a fragmentação presente nas especialidades médicas. Impõe-se assim uma reflexão em torno desta figura e suas possibilidades, bem como uma redefinição do termo Psicologia Clínica no que diz respeito a sua caracterização, ao objeto de sua intervenção, assim como objetivos e metas a serem atingidos.

A partir dos dacios aqui levantados, concluise da importância do reconhecimento do Psicólogo, por parte da população, profissionais e funcionários, numa equipe de saúde, no que diz respeito a sua especificidade, modo de trabalho e objetivos a serem desenvolvidos na sua prática. Através de mensagens claras que contemplam o saber do senso comum e o saber acadêmico científico é que as ações do Psicólogo atingirão sua efetividade e eficácia, no sentido de uma melhor escuta, junto às camadas populares e às instituições de atendimento público $\mathrm{e}$ gratuito.

Em termos teóricos destacamos que o nível das representações sociais constitui-se num componente cultural inerente ou indissociável do contexto social, sendo seu reconhecimento imprescindível para um melhor entendimento e compreensão das ações realizadas pelos profissionais e pessoas inseridas no sistema de saúde público-comunitário no Brasil.

\section{Referências Bibliográficas}

Ancona Lopez, M. (1983). Considerações sobre atendimento fornecido por clínicas-escola de Psicologia.Arquivos Brasileiros de Psicologia. 35,(2), p.5-11.

Bernardes, N.M.G. (1991). Análise compreensiva de base fenomenológica e o estudo da experiência vivida de crianças e adultos. Educação, 20, p.15 $-40$.

Bohoslavky, R. (1968). Que es la psicología clíni$c a$ ? Texto apresentado na Universidade Nacional de Buenos Aires. (Mimeo Orbe).
Carvalho, A.M.A. (1983). Modalidades alternativas de trabalho para Psicólogos recém-formados. 36 ${ }^{a}$ Reunião Anual.da SBPC (p. 626). Belém. PA.

Conferência Nacional de Saúde Mental (1992). 2 da. Etapa estadual. Florianópolis.Relatório Final.

Delgado, P. (1991). Projeto de Lei sobre Política de Saúde Mental. Apresentado para a aprovação pela Câmara dos Deputados e Senado Federal. Brasilia.

JODELET, D. (1989). Representation Sociale : um domaine en expansion. Em D. Jodelet (Org.), Les Représentations Sociales, Paris, P.U.F., p.31-61

Larrabure, S.A.L. (1984). Grupos de espera em Instituições. Em R. Macedo (Org), Psicologia e Instituição: Novas formas de atendimento. São Paulo: Cortez,

Macedo, R.M. (1984). Psicologia e Instituição. Novas formas de atendimento. São Paulo: Editora Cortez.

Mello, L. (1975). Psicologia e profissão em São Paulo. São Paulo: Editora Ática.

Moscovici, S. \& Farr, R. (1984). Social Representations. Cambridge: University Press.

\section{ANEXO 1 - MODELOS DOS QUESTIONÁRI- OS}

A - Questionários respondidos pelos profissionais

1. O que você sabe ou pensa a respeito da Psicolgia como ciência?

2. Você sabe o que faz um psicólogo?

3. Que pessoas, no seu entender, precisariam de psicólogo?

4. No seu entender, quais são as diferenças em termos de especificidade profissional entre Psicólogo e Psiquiatra no campo da Saúde Mental?

5. No seu entender, o que é saúde e o que é doença?

B - Questionário respondido pelos funcionários

1. O que você sabe ou pensa que é a Psicologia?

2. Você sabe o que faz um psicólogo? 
1. O que você sabe ou pensa que é a Psicologia?

2. Você sabe o que faz um psicólogo?

3. Que pessoas, no seu entender, precisariam de psicólogo?

4. Você sabe a diferença entre psicólogo, psiquiatra e médico de um modo geral?

5. No seu entender, o que é saúde e o que é doença?

6. Qual dos seguintes problemas você tentaria resolver primeiro?

6.1 - Problemas de doença física;

6.2 - Problemas pessoais ou conflitos familiares;

6.3 - Problemas de trabalho e moradia;

6.4 - Os problemas acima possuem todos a mesma importância.

C - Questionário respondido pelos pacientes

1. Por quem você foi encaminhado ao serviço de Psicologia?

2. Você sabe o que faz um psicólogo?

3. Que pessoas, no seu entender, precisariam de psicólogo?

4. Você sabe a diferença entre psicólogo, psiquiatra e médico de um modo geral?

5. No seu entender, o que é saúde e o que é doença?

6. Qual dos seguintes problemas você tentaria resolver primeiro?

6.1 - Problemas de doença física;

6.2 - Problemas pessoais ou conflitos familiares;

6.3 - Problemas de trabalho e moradia;

6.4 - Os problemas acima possuem todos a mesma importância. 